\title{
Selective activation of cannabinoid receptor 2 regulates Treg/Th17 balance to ameliorate neutrophilic asthma in mice
}

\author{
Chaochao Wei, Linhui Huang, Yamei Zheng, Xingjun Cai^^ \\ Department of Pulmonary and Critical Care Medicine, Hainan General Hospital, Haikou, China \\ Contributions: (I) Conception and design: C Wei, X Cai; (II) Administrative support: C Wei; (III) Provision of study materials or patients: L Huang, \\ Y Zheng; (IV) Collection and assembly of data: C Wei, L Huang, Y Zheng; (V) Data analysis and interpretation: X Cai; (VI) Manuscript writing: All \\ authors; (VII) Final approval of manuscript: All authors. \\ Correspondence to: Professor Xingjun Cai. Department of Pulmonary and Critical Care Medicine, Hainan General Hospital, No. 19 Xiuhua Road, \\ Xiuying District, Haikou 570311, China. Email: caixingjun6535@163.com.
}

Background: The cannabinoid receptor 2 (CNR2) plays a critical role in relieving asthma, with the
mechanism still unclear. We aimed to investigate the mechanism of the CNR2 agonist ( $\beta$-caryophyllene,
$\beta$-Car) in regulating the balance of regulatory T cells (Treg) and T helper cell 17 (Th17) and thus its role in
asthma.
Methods: The study group of 50 pathogen-free female BALB/c mice were randomly divided at $6-8$ weeks
old into five groups of Control, Asthma, Asthma + $\beta$-Car ( $10 \mathrm{mg} / \mathrm{kg}$ ), Asthma + $\beta$-Car + SR144528 (specific
CNR2 antagonist, $3 \mathrm{mg} / \mathrm{kg}$ ), and Asthma + $\beta$-Car + CMD178 (inhibitor of Treg cell, $10 \mathrm{mg} / \mathrm{kg}$ ). ELISA was
conducted to evaluate the main inflammatory cytokines [interleukin (IL)-6, IL-8, and tumor necrosis factor- $\alpha$,
and those secreted by Treg (transforming growth factor- $\beta$ and IL-10), and Th17 (IL-17A and IL-22).
Markers of Treg and Th17 cells were assessed by flow cytometry. In vitro, the CD4 ${ }^{+}$T cells were sorted and
directed to differentiate to Treg and Th17 cells. The expression levels of CNR2, STAT5 and JNK1/2 were
investigated by western blot and immunofluorescence assay. Results: $\beta$-Car relieved neutrophilic asthma severity in mice by elevating the marker genes' expression of Treg and inhibiting those of Th17, causing an increased proportion of Treg to Th17. $\beta$-Car also promoted the directed differentiation of $\mathrm{CD}^{+} \mathrm{T}$ cells into Treg, but not Th17. Activation of the CNR2 regulated the Treg/Th17 balance and relieved neutrophilic asthma possibly through promotion of phosphorylation of STAT5 and JNK1/2.

Conclusions: The effect of the selective CNR2 agonist activating STAT5 and JNK1/2 signaling was to change the Treg/Th17 balance and reduce the inflammatory reaction, thus ameliorating neutrophilic asthma in a mouse model.

Keywords: CB2 receptor; inflammation; neutrophilic asthma; T helper cell 17 (Th17); Treg

Submitted May 07, 2021. Accepted for publication Jun 09, 2021.

doi: $10.21037 /$ atm-21-2778

View this article at: https://dx.doi.org/10.21037/atm-21-2778

\section{Introduction}

Bronchial asthma (herein termed "asthma") is a chronic airway inflammatory respiratory disease with complex etiology. Its morbidity and mortality have increased significantly in recent years, affecting nearly 300 million people, with $10-15 \%$ suffering from severe asthma, making it a severe public health problem worldwide. The severity and mortality of adult asthma were increased in active and

^ ORCID: 0000-0002-4178-8426. 
passive smoking patients. Among asthmatic subjects who smoke, the frequency of acute attacks and the severity of symptoms significantly increase (1). At present, treatment consists of inhaled corticosteroids, leukotriene receptor antagonist, and other drugs, but not all asthma patients are controlled or cured and there are side effects (2). Therefore, in-depth research on the pathogenesis of asthma and finding new drug targets are of great significance for both preventing and treating asthma.

Asthma can be divided into eosinophilic, neutrophilic, and mixed forms (3). Approximately 50\% of patients with severe asthma have the neutrophilic from (4). Moreover, researchers believe that the occurrence of neutrophilic asthma is smoking-related, with more exposure inducing a greater proportion of neutrophils and aggravation of the disease (3-6). Neutrophilic asthma is typically characterized by neutrophil infiltration and increased chemokine, interleukin (IL)-8 $(3,4)$. Neutrophils induces the proliferation and secretion of mucous glands by releasing cytokines IL-1, -6 and -8 , as well as leukotrienes, elastase (ELA2) and reactive oxygen species, which leads to smooth muscle cell proliferation and contraction of bronchial smooth muscle, thus causing airway remodeling and chronic airway inflammation (7). T helper cell 17 (Th17) and its secreted cytokines play an important role in the infiltration of neutrophils. Th17 stimulates airway epithelial cells and fibroblasts to secrete the neutrophil chemokines IL-8 (CXCL8), CXCL1/Growth-related oncogene-alpha (GROalpha), and granulocyte macrophage stimulating factor (GM-CSF) by secreting IL-17A and $-17 \mathrm{~F}$, thus recruiting neutrophils and enhancing their infiltration of the airways and lung tissues (4). Therefore, regulating the quantity and activity of Th17 cells is of great significance for preventing and treating neutrophilic asthma.

Regulatory $\mathrm{T}$ cells (Treg) are a $\mathrm{CD} 4{ }^{+} \mathrm{CD} 25^{\text {high }}$ $\mathrm{CD} 127^{\text {low }} /-\mathrm{Foxp}^{+}{ }^{+}$regulatory $\mathrm{T}$ cell 5 group that regulates the inflammatory response in allergic diseases, and are important in maintaining immune tolerance (8). Peripheral Treg and Th17 cells can be formed by differentiation of $\mathrm{CD}^{+} \mathrm{T}$ cells, of which Treg is differentiated depending on the activity of signal transducer and activator of transcription 5 (STAT5) and forkhead/winged helix transcription factor (FOXP3), which are regulated by transforming growth factor- $\beta$ (TGF- $\beta$ ) or IL-2, while Th17 is differentiated according to retinoid-related orphan nuclear receptor $\gamma \mathrm{t}(\mathrm{ROR} \gamma \mathrm{t})$ activity regulated by TGF- $\beta$, IL-1 or IL-6 (9). Treg suppress the immune response by inhibiting cytokine production and effector $\mathrm{T}$ cell proliferation, thereby affecting the Th1/Th2 balance and Th17 cell differentiation (10-12). However, in an analysis of asthma by Zou et al. (12), they demonstrated that it was Treg/Th17 homeostasis, not Th1/Th2 homeostasis that was implicated in exacerbating human bronchial asthma. Therefore, we selected Treg/Th17 as the main research object.

So far, two different cannabinoid receptors (CBs) have been discovered, of which CB1 is a central receptor distributed in the brain, and CB2 is a peripheral receptor distributed in the immune system, including the spleen, lymph nodes, and lymphocytes (13-15). Notably, the expression of the CB2 receptor (CNR2) outside the central nervous system, especially in immune systemrelated tissues and cells, has attracted increasing interest regarding regulation of immune function. The CNR2 may be involved in the airway immune function and the process of allergy, and affect the occurrence and development of asthma $(16,17)$. Moreover, the neutrophil count in the bronchoalveolar lavage fluid (BALF) of asthmatic mice exposed to tobacco smoke linearly negatively correlated with CNR2 protein expression in lung tissue (18). Wang et al. (19) found that after treatment with the CNR2 agonist GP1a for a traumatic wound in mice, the infiltration of neutrophils and macrophages was reduced, and the levels of inflammatory factors (IL-6, IL- $1 \beta$, and TNF- $\alpha$, etc.) and TGF- $\beta$ declined. Lowin et al. $(20,21)$ found that the CB receptor agonist WIN (WIN55, 212-2 mesylate) inhibited the expression of IL-6, IL-8, and other inflammatory factors through the CNR2 in their research of rheumatoid arthritis. In a study of guinea pigs, Fukuda et al. (22) revealed that WIN inhibited C-fiber activation by activating the CNR2, thereby inhibiting the airway inflammation caused by the antigen. Therefore, activating the CNR2 might alleviate neutrophilic asthma by reducing neutrophil infiltration, and inhibiting expression of inflammatory cytokines. However, the mechanism of CB2's effect in neutrophilic asthma is still unclear.

We speculated that CNR2 agonists could alleviate the symptoms of neutrophilic asthma by regulating the differentiation and activity of Treg, inhibiting Th17 differentiation, changing the balance of Treg/Th17, and producing an immunosuppressive response. In the present study, the in vivo and in vitro experiments were designed to determine whether the CNR2 agonists have immunoregulatory effects on the Treg/Th17 balance in a murine ovalbumin-induced neutrophilic asthma model, and if so, how. We present the following article in accordance 
with the ARRIVE reporting checklist (available at https:// dx.doi.org/10.21037/atm-21-2778).

\section{Methods}

\section{Reagents}

The Ovalbumin (OVA) (90\%, DH015-4) was obtained from Guangzhou Dingguo Biotechnology Co., Ltd. $\beta$-Caryophyllene ( $\beta$-Car; HY-N1415), SR144528 (HY13439), and CMD178 (HY-P1453) were purchased from MedChemExpress (Monmouth Junction, NJ, USA). Cigarettes were obtained from Red Double Happiness Cigarette Shanghai Cigarette Factory. All-trans retinoic acid (ATRA), RPMI-1640 medium, and 10\% fetal bovine serum (cat. no. 10099-141) was bought from BD Biosciences (San Jose, CA, USA), Thermo Fisher Scientific (Waltham, MA, USA), and Gibco (Grand Island, NY, USA), respectively. We bought phorbol ester $(500.0 \mathrm{ng} / \mathrm{mL})$, ionomycin $(1.0 \mu \mathrm{g} / \mathrm{mL})$, and monensin $(0.1 \mathrm{mg} / \mathrm{mL})$ from SigmaAldrich (St. Louis, MO, USA).

\section{Animals and grouping}

We purchased 50 specific pathogen-free female BALB/ c mice (weight: $18-20 \mathrm{~g}$ ) at 6-8 weeks old from the Laboratory Animal Center of Southern Medical University. Experiments were performed under a project license (No.: 202005-08) granted by institutional Ethics Committee Board of Hainan General Hospital, in compliance with international ethical guidelines and the National Institutes of Health Guide concerning the Care and Use of Laboratory Animals. The animals were housed at a controlled temperature of $20-26^{\circ} \mathrm{C}$ and $40-70 \%$ relative humidity, with ad libitum food and drink.

The mice were sensitized and challenged with OVA, as previously described $(23,24)$. On experiment days 0,7 , and 14, $20 \mu \mathrm{g}$ OVA adsorbed with $100 \mu \mathrm{g} / \mathrm{mL}$ of Imject Alum were injected intraperitoneally. On day 14, mice were anesthetized and treated with $100 \mu \mathrm{g}$ OVA in $50 \mu \mathrm{L}$ phosphate-buffered saline (PBS) intranasally or PBS alone for negative control (unsensitized mice). On days 25-27, the treatment was repeated with $50 \mu \mathrm{g}$ OVA in $50 \mu \mathrm{L}$ PBS, except for intraperitoneal injection of farrerol at 20 and $40 \mathrm{mg} / \mathrm{kg}$ and dexamethasone $(2 \mathrm{mg} / \mathrm{kg}) 1 \mathrm{~h}$ prior to OVA administration.

Passive smoking was performed $30 \mathrm{~min}$ after OVA stimulation, with 10 cigarettes each time for $1 \mathrm{~h}$ until the end of the experiment. The mice were randomly divided into five groups ( $\mathrm{n}=10)$ : (I) control (Control); (II) cigarette exposure neutrophilic asthma (asthma); (III) cigarette exposure neutrophilic asthma treated with the CNR2 agonist $\beta$-Car $(10 \mathrm{mg} / \mathrm{kg})$ (asthma $+\beta$-Car); (IV) cigarette exposure neutrophilic asthma treated with $\beta$-Car and the CNR2 antagonist SR144528 (3 mg/kg) (asthma + $\beta$-Car + SR144528); and (V) cigarette exposure neutrophilic asthma treated with $\beta$-Car and Treg activity inhibitor CMD178 (10 mg/kg) (asthma + $\beta$-Car + CMD178). After the stimulation, the mice in asthma model group had typical asthma symptoms such as sneezing, nodding and breathing, shortness of breath, wheezing, abdominal muscle contraction and irritability. Rapid respiration, cyanosis of the lips and limbs, and instability of stance were taken as successful passive smoking effect.

\section{Collection of blood samples and BALF}

On the day after the last antigen challenge and passive smoking, each mouse was anesthetized by intraperitoneal injection of $1.5 \%$ pentobarbital and the chest cavity was opened to collect blood from the right ventricle into a heparin-washed 1-mL syringe. The trachea in the front of the neck of the mouse was exposed, a transverse incision was made, and a modified $18 \mathrm{G}$ tracheal intubation needle was inserted. The left lung was lavage three times with $0.4 \mathrm{~mL}$ PBS, with a recovery rate $>80 \%$. The BALF was collected in a $1.5-\mathrm{mL}$ centrifuge tube, centrifuged at $625 \mathrm{~g}, 4^{\circ} \mathrm{C}$ for $7 \mathrm{~min}$, and resuspended with PBS. The hilum of the right lung was ligated with silk thread, then the sample of right lung tissue was excised, placed in a cryotube, and stored at $-80^{\circ} \mathrm{C}$ after rapid freezing with liquid nitrogen.

We removed $100 \mu \mathrm{L}$ of the BALF cell suspension, added $100 \mu \mathrm{L}$ white blood cell counting solution (Beyotime, Shanghai, China) and mixed it well, before counting the total number of white blood cells under a microscope with a hemocytometer (Phenix, Shangrao, China). The cell slide was stained with Swiss-Giemsa (Beyotime), and the cells were sorted and counted in parallel. Each sample counted 200 white blood cells, comprising eosinophils, neutrophils, lymphocytes and macrophages, to obtain the percentages of the various types of cells and then calculated the absolute value. The single-blind method was used for cell counting, all completed by the same researcher.

\section{Enzyme-linked immunosorbent assay (ELISA)}

ELISA was performed on the BALF supernatant to 
determine the concentration of cytokines (IL-6, -8, -10, $-17 \mathrm{~A}$, and-22, TNF- $\alpha$, TGF- $\beta$ ). The levels of IL-17A, -22, and -10 in the cell culture supernatant were also assessed according to the kit's instructions. The detection kits of mouse IL-6 (MEIMIAN14206), IL-8 (MEIMIAN4103), TNF- $\alpha$ (MEIMIAN920), IL-17A (MEIMIAN9401), IL-22 (MEIMIAN12178), TGF- $\beta$ (MEIMIAN2 1034), and IL-10 (MEIMIAN4502) were bought from Jiangsu Enzyme Industry Co., Ltd. (Nanjing, China). The optical density (OD) value at $450 \mathrm{~nm}$ wavelength was determined using a BioTek Microplate Reader System (BioTek, Winooski, VT, USA).

\section{Cell sorting, differentiation, and grouping in vitro}

$\mathrm{BALB} / \mathrm{c}$ mice were humanely killed by cervical dislocation, and their spleens removed. The spleen mononuclear cell suspension was obtained by trypsin digestion, and the $\mathrm{CD}^{+} \mathrm{T}$ cells were sorted using a $\mathrm{CD}^{+} \mathrm{T}$ cell immunomagnetic bead sorting kit. The detailed method is provided in Supplementary file (Appendix 1).

The respective microenvironments for directed differentiation and maturation of $\mathrm{CD}^{+}{ }^{+} \mathrm{T}$ cells into Treg cells and Th17 cells were prepared. For Treg cells, we added the $\alpha$-T cell receptor $(\alpha$-TCR) $\alpha$-TCR stimulator (anti$\mathrm{CD}^{+}, 5 \mu \mathrm{g} / \mathrm{mL}$; anti-CD28, $5 \mu \mathrm{g} / \mathrm{mL}$ ) and the cytokines ATRA $(20 \mathrm{mg} / \mathrm{mL}), \mathrm{IL}-2(100 \mathrm{U} / \mathrm{mL})$, and TGF- $\beta$ $(100 \mu \mathrm{g} / \mathrm{mL})$. For Th17 cells, we added the $\alpha$-TCR stimulator of anti-CD3 $(5 \mu \mathrm{g} / \mathrm{mL})$ and anti-CD2 8 $(5 \mu \mathrm{g} / \mathrm{mL})$, and the cytokines IL-1 $\beta$ (20 $\mathrm{ng} / \mathrm{mL})$, IL-6 (20 ng/mL), and TGF- $\beta(100 \mu \mathrm{g} / \mathrm{mL})$.

The cells were cultured using RPMI-1640 medium supplemented with penicillin and streptomycin $(100 \mu \mathrm{g} / \mathrm{mL})$ and $10 \%$ fetal bovine serum. Cells were randomly separated into seven groups: (I) stock culture group (anti-CD3 ${ }^{+}$antiCD28; Control); (II) Treg directed-differentiation group without intervention $\left[\right.$ anti-CD $3^{+}$anti-CD28+ IL-2 $(100 \mathrm{U} / \mathrm{mL})+$ TGF- $\beta(100 \mu \mathrm{g} / \mathrm{mL}) ;$ Treg-DD]; (III) directed differentiation of Treg $+\beta$-Car $(5 \mu M)$ intervention group (Treg-DD + $\beta$-Car); (IV) Treg directional differentiation $+\beta-$ Car + CNR2 antagonist SR144528 (0.6 $\mathrm{nM}$ ) combined intervention group (Treg-DD + $\beta$-Car + SR144528); (V) Th17 directed differentiation without intervention group (anti-CD3 ${ }^{+}$anti-CD28 + IL$1 \beta+$ IL-6 + TGF- $\beta$; Th17-DD); (VI) Th17 directional differentiation $+\beta$-Car $(5 \mu \mathrm{M})$ intervention group (Th17 $+\beta$-Car); (VII) Th17 directional differentiation $+\beta$-Car + CNR2 antagonist SR144528 (0.6 nM) combined intervention group (Th17-DD + $\beta$-Car + SR144528).

The $\alpha$-TCR stimulator and the cytokines required for differentiation in each intervention group were added to the culture medium first. During the 6 days of differentiation culture, CNR2 agonist or CNR2 antagonist SR144528 was added once every $24 \mathrm{~h}$, and all cells were cultured in a $37{ }^{\circ} \mathrm{C}, 5 \% \mathrm{CO}_{2}$ incubator. After induction, the supernatant and cells were isolated.

\section{Histopathology and immunohistochemistry}

The sample of right lung tissue was divided into two parts, with one part fixed with $4 \%$ formaldehyde for 24 h at room temperature and subsequently transferred into PBS. Before staining with hematoxylin and eosin ( $\mathrm{HE})$, the lung tissues were dehydrated and embedded in paraffin, and $4 \mu \mathrm{m}$ sections were observed under a microscope (Phenix).

Moreover, the sections were also used for immunohistochemical analysis after deparaffinization and refilling in xylene. Immunohistochemistry was performed according to the standard method (25). Endogenous peroxidase was inhibited with $0.5 \%$ hydrogen peroxide in methanol for $10 \mathrm{~min}$, and then the slides were incubated with rabbit polyclonal IgG antibodies against the CNR2 (Abcam, Cambridge, MA, USA) at $48{ }^{\circ} \mathrm{C}$ for $12 \mathrm{~h}$. We used biotinylated goat anti-rabbit IgG reagent, horseradish peroxidase (HRP) reagent (Abcam), and diaminobenzidine for immunoassay. Image pro plus 6.0 was used to analyze the average OD (AOD) of the CNR2 under $\times 100$ and $\times 400$ objective lenses.

\section{Real-time quantitative PCR (RT-qPCR)}

The second part of the right lung tissue was frozen in liquid nitrogen for a few minutes and then transferred to $-80{ }^{\circ} \mathrm{C}$ for real-time quantitative PCR (RT-qPCR) and western blot (WB) analysis. The expression levels of STAT5, ROR $\gamma$, and $F O X P 3$ in the right lung tissues were evaluated by ${ }_{\mathrm{q}} \mathrm{PCR}$ analysis. Moreover, the expression levels of CNR2, STAT5, $R O R \gamma t$, and FOXP3 in the cells were also assessed. A total of $5 \mu \mathrm{g}$ RNA from each group were obtained by TRIzol (\#9109, TAKARA, China) and used as the template to form cDNA using Bestar ${ }^{\mathrm{TM}}$ qPCR RT kit (\#2220, DBI Bioscience, China). Subsequently, cDNA was amplified by qPCR on a Stratagene Mx3000P real-time PCR instrument (MX3000P, Stratagene, USA) using Bestar ${ }^{\text {TM }}$ qPCR Master Mix (\#2043, DBI Bioscience) according to the manufacturers' protocols. The sequence of primers for CNR2, STAT5, ROR $\gamma t$, and FOXP3 is provided in Table $\mathrm{S} 1$. GAPDH was used as 
endogenous control. The reactions and PCR amplification were performed under standard techniques (26).

\section{Western blot}

Total proteins were isolated from right lung tissue $(50 \mu \mathrm{g})$ and cells $\left(5 \times 10^{6}\right)$ using RIPA buffer (\#89900; Thermo Scientific, Worcester, MA, USA) containing a protease inhibitor cocktail (\#P2714; Sigma) and phosphatase inhibitor cocktail (\#04906845001; Roche Applied Science, Indianapolis, IN, USA). Homogenates were centrifuged at $2,834 \mathrm{~g}$ at $4{ }^{\circ} \mathrm{C}$ for $20 \mathrm{~min}$ before the supernatant was collected. The total protein concentrations were determined by bicinchoninic acid assay (\#23227, Pierce ${ }^{\mathrm{TM}}$ Biotechnology, Rockford, IL, USA). Standard SDS-PAGE technique (27) was performed on equal amounts of proteins, with antibodies of p-STAT5 (ab32364; 1:500), ROR $\gamma$ t (ab135669; 1:500), FOXP3 (ab215206; 1:500), JNK (ab112501; 1:500), p-JNK (ab4821; 1:500), arachidonate 5-lipoxygenase (Alox5; ab169755; $1: 500)$, activator protein 1 (AP-1, ab21981; 1:500), and GAPDH (ab181602; 1:500) obtained from Abcam. The band intensity was measured by ImageJ2× 2.1.4.7 (Wayne Rasband, National Institutes of Health, USA).

\section{Flow cytometry}

The numbers of Treg and Th17 cells were detected using flow cytometry. $\mathrm{CD} 4{ }^{+} \mathrm{CD} 25^{+}$cells were incubated with phorbol ester, ionomycin, and monensin for $4 \mathrm{~h}$ at $37^{\circ} \mathrm{C}$ under $5 \% \mathrm{CO}_{2}$. Next, the cells were washed twice with PBS and incubated with FITC-labeled anti-CD4 at $4{ }^{\circ} \mathrm{C}$ for $45 \mathrm{~min}$. Cells were fixed and permeabilized, stained with FITC-labeled anti-CD4 $4^{+}$, APC-labeled anti-CD25, PE-labeled anti-IL-17A, PE-labeled anti-FOXP3, and PE-labeled anti-ROR $\gamma \mathrm{t}$ monoclonal antibodies (BD Biosciences), and then incubated at $4{ }^{\circ} \mathrm{C}$ for $30 \mathrm{~min}$. Guava easyCyte $^{\mathrm{TM}}$ Cytometer system (Merck Millipore, Germany) was used for the flow cytometric analysis, the data from which were analyzed by the software provided by the Cytometer system.

\section{Statistical analysis}

SPSS 20.0 (SPSS, Chicago, IL, USA) and GraphPad Prism 8 (GraphPad Software, San Diego, CA, USA) were used for statistical analysis and visualization, respectively. Comparisons between groups were conducted using the $t$-test, and the results with $\mathrm{P}<0.05, \mathrm{P}<0.01$, and $\mathrm{P}<0.001$ were considered statistically significant. Data were expressed as mean \pm standard deviation (SD).

\section{Results}

\section{Effect of $\beta$-Car on inflammation and Treg/Th17 balance in asthmatic mice}

HE staining of lung tissue was performed to detect airway and morphological changes in OVA-sensitized neutrophilic asthmatic mice exposed to tobacco smoke after $\beta$-Car treatment. As compared with the Control group, inflammatory cells, including eosinophils, neutrophils, and lymphocytes, abundantly infiltrated around the bronchioles and vessels in the right lung tissues of the Asthma groups (Figure 1A). Treatment with $\beta$-Car suppressed the infiltration of inflammatory cells compared with the Asthma groups, which was reversed by the administration of Treg inhibitor (CMD178) and CNR2 antagonist (SR144528). The levels of inflammatory cytokines, including IL-6, IL-8, and TNF- $\alpha$, were evaluated in the right lung tissue. As shown in Figure 1B,C,D, the levels of the three main cytokines (IL-6, IL- $8, \mathrm{TNF}-\alpha$ ) that promote the inflammatory response were significantly increased in the neutrophilic asthma groups compared with Control $(\mathrm{P}<0.001)$. In the $\beta$-Car administration group (Asthma + $\beta$-Car), they were significantly decreased compared with the Asthma group $(\mathrm{P}<0.001)$. The IL- 6 and TNF- $\alpha$ levels were found to increase significantly in Asthma $+\beta$-Car treated with CNR2-specific antagonist SR144528 (Asthma $+\beta$-Car + SR144528) compared with Asthma $+\beta$-Car alone $(\mathrm{P}<0.05 ; \mathrm{P}<0.01)$. No significantly differences were observed in IL- 8 between the Asthma $+\beta$-Car + SR144528 and Asthma $+\beta$-Car groups $(\mathrm{P}>0.05)$. However, in mice treated with Treg activity inhibitor CMD178 (Asthma + $\beta$-Car + CMD178), the levels of IL-6, IL-8, and TNF- $\alpha$ were significantly higher than in Asthma $+\beta-\mathrm{Car}(\mathrm{P}<0.001)$. The results indicated that activation of the CNR2 had a significant effect on alleviating inflammation in mice with cigarette smoke stimulation combined with neutrophilic asthma, suggesting that the status of the CNR2 may play an important role in neutrophilic asthma.

As demonstrated by these reported results, the Treg/ Th17 balance might be disturbed by $\beta$-Car, with increased Treg. Therefore, the key cytokines secreted by Treg (TGF- $\beta$ and IL-10) and Th17 (IL-17A and IL-22) were evaluated. The results showed that IL-10, TGF- $\beta$, IL-17A, and IL-22 were significantly increased in Asthma mice compared 


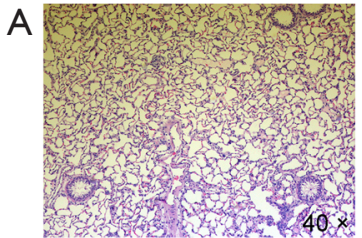

Control

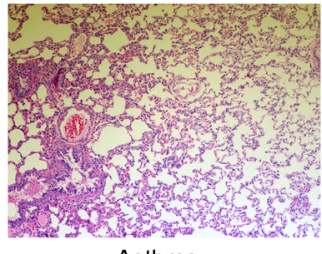

Asthma

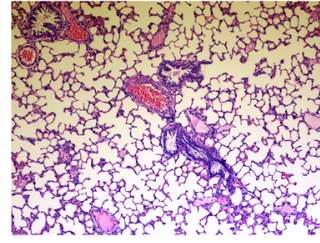

Asthma $+\beta$-car

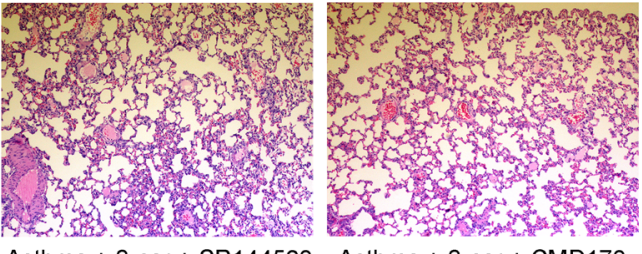

Asthma + $\beta$-car + SR144528 Asthma + $\beta$-car + CMD178
B

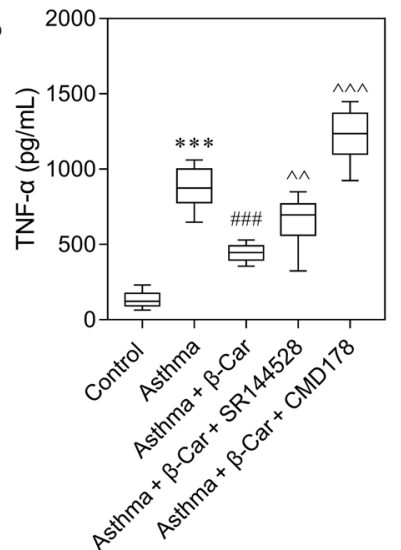

F

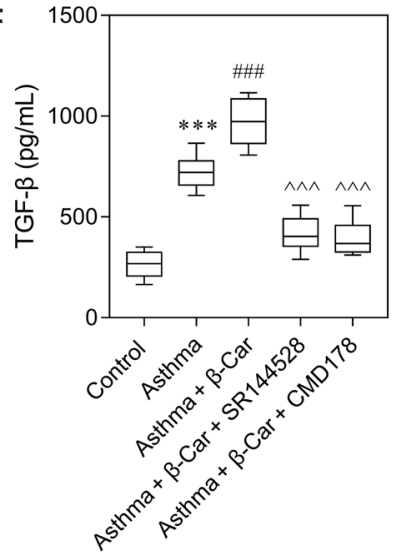

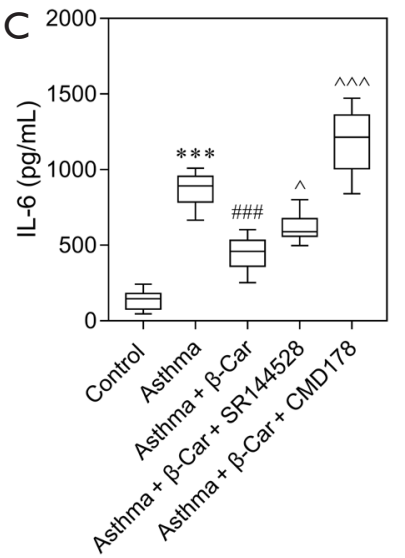

G

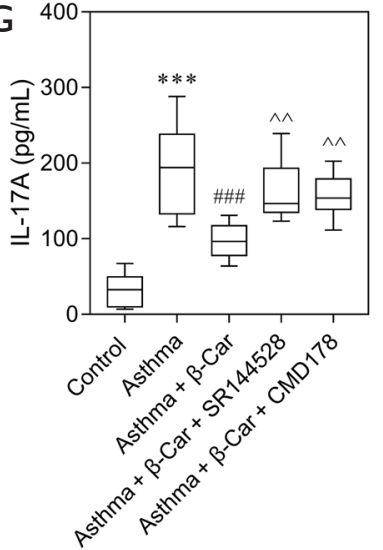

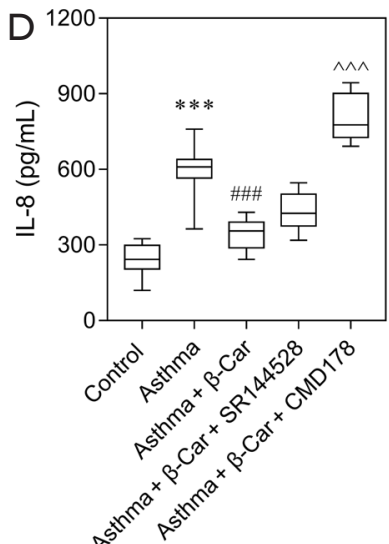
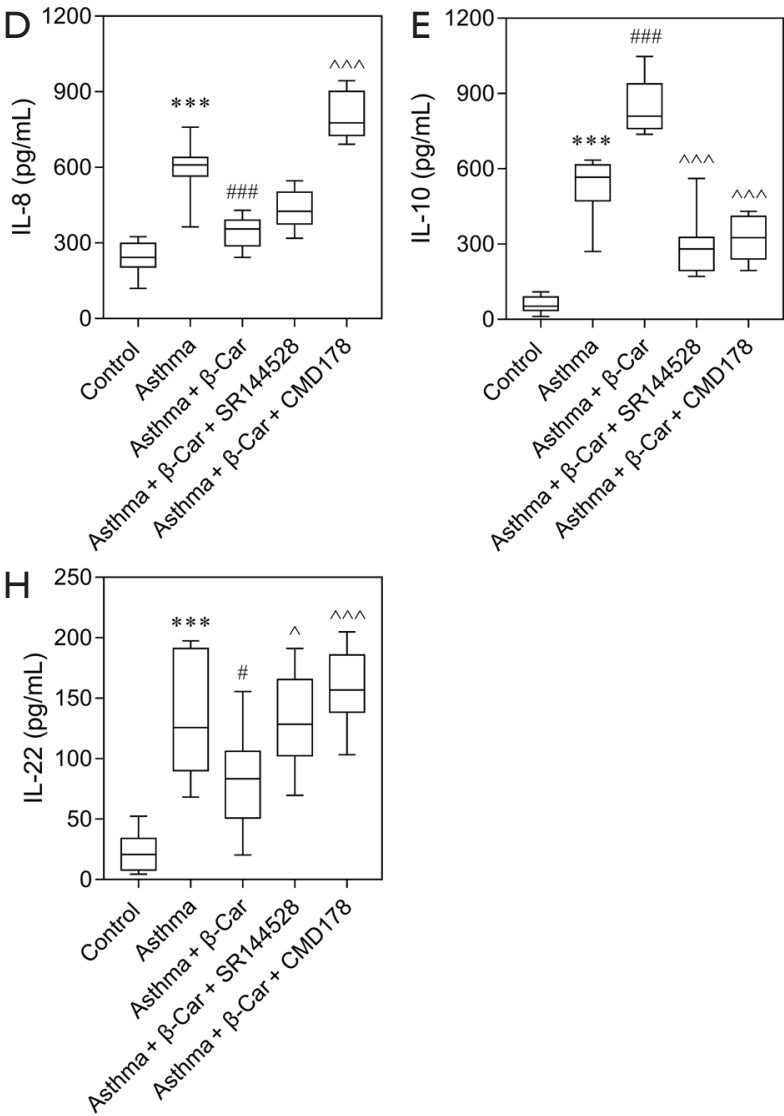

Figure 1 Effect of $\beta$-Car on pulmonary inflammation in neutrophilic asthma. Bronchial asthma was induced in mice by tobacco smoke exposure and ovalbumin stimulation ( $\mathrm{n}=10)$, and subsequently administered $\beta$-Car, SR144528 or CMD178. SR144528 is a $\beta$-Car antagonist and CMD178 is a Treg inhibitor. (A) Lung tissue samples of the asthmatic mice were stained with hematoxylin \& eosin and observed under a microscope (40×); (B,C,D) levels of inflammatory cytokines (TNF- $\alpha$, IL-6, IL-8) assessed by ELISA; (E,F) levels of the cytokines IL10 and TGF- $\beta$ secreted by Treg as assessed by ELISA; (G,H) levels of the cytokines IL-17A and IL-22 secreted by Th17 as assessed by ELISA. ${ }^{* *} \mathrm{P}<0.001$ vs. Control group; ${ }^{\#} \mathrm{P}<0.05,{ }^{\# \# \#} \mathrm{P}<0.001$ vs. Asthma group; ${ }^{\wedge} \mathrm{P}<0.05,{ }^{\wedge \wedge} \mathrm{P}<0.01,{ }^{\wedge \wedge} \mathrm{P}<0.001$ vs. Asthma $+\beta-$ Car group. $\beta-$ Car, $\beta$-caryophyllene; ELISA, enzyme-linked immunosorbent assay; IL, interleukin; TGF, transforming growth factor; TNF, tumor necrosis factor; Treg, regulatory $\mathrm{T}$ cell.

with Control mice $(\mathrm{P}<0.001$; Figure 1E,F,G,H). In response to the administration of $\beta$-Car, the levels of TGF- $\beta$ and IL-10 significantly increased $(\mathrm{P}<0.001)$, while those of IL$17 \mathrm{~A}$ and IL-22 significantly decreased $(\mathrm{P}<0.05 ; \mathrm{P}<0.001)$ in the Asthma+ $\beta$-Car group compared with the Asthma group.
Besides, the CNR2 antagonist, SR144528, and Treg activity inhibitor CMD178 significantly reversed the levels of IL-10, TGF- $\beta$, IL-17A, and IL-22 that had been increased by $\beta$-Car $(\mathrm{P}<0.05, \mathrm{P}<0.01, \mathrm{P}<0.001)$. The results indicated that activation of $\beta$-Car might promote Treg cells while 
Table 1 Effect of $\beta$-Car administration on levels of lymphocytes, eosinophils, and neutrophils in mice

\begin{tabular}{lccr}
\hline Group & Eosinophils $\left(1 \times 10^{6} / \mathrm{mL}\right)$ & Neutrophils $\left(1 \times 10^{6} / \mathrm{mL}\right)$ & Lymphocyte $\left(1 \times 10^{8} / \mathrm{mL}\right)$ \\
\hline Control & $2.31 \pm 0.81$ & $73.25 \pm 9.21$ & $1.35 \pm 0.42$ \\
Asthma & $10.05 \pm 2.05^{\star \star \star}$ & $162.58 \pm 25.21^{\star \star \star}$ & $6.68 \pm 2.36^{\star \star \star}$ \\
Asthma + $\beta$-car & $8.62 \pm 1.76^{\# \# \#}$ & $95.21 \pm 22.89^{\# \# \#}$ & $3.02 \pm 1.84^{\# \# \#}$ \\
Asthma + $\beta$-car + SR144528 & $11.02 \pm 2.84^{\wedge \wedge}$ & $176.29 \pm 31.95^{\wedge \wedge}$ & $7.27 \pm 3.05^{\wedge \wedge}$ \\
Asthma + $\beta$-car + CMD178 & $12.26 \pm 3.61^{\wedge \wedge}$ & $169.45 \pm 35.65^{\wedge \wedge}$ & $7.15 \pm 3.19^{\wedge \wedge}$ \\
\hline
\end{tabular}

${ }^{\star \star *} \mathrm{P}<0.001$ vs. Control group; ${ }^{\# \# \#} \mathrm{P}<0.001$ vs. Asthma group; ${ }^{\wedge \wedge} \mathrm{P}<0.001$ vs. Asthma $+\beta$-Car group; SR144528 is CB2 antagonist and CMD178 is Treg inhibitor. Each experiment was triplicate. $\beta$-Car, $\beta$-caryophyllene; $C B$, cannabinoid; Treg, regulatory $T$ cell.

inhibiting Th17 cells. However, whether activation of the CNR2 has a substantial protective effect on the lungs and the specific mechanism by which it affects the balance of Treg cells/Th17 cells remain to be investigated in further experimental work.

\section{In vivo effect of activating CNR2}

The numbers of inflammatory cells, including lymphocytes, eosinophils, and neutrophils, were counted and all were significantly increased in the mice subjected to cigarette smoke environment and induced with neutrophilic asthma compared with Control mice $(\mathrm{P}<0.001$; Table 1). However, treatment with $\beta$-Car significantly decreased the cell numbers $(\mathrm{P}<0.001)$, which was reversed by CMD178 and SR144528 $(\mathrm{P}<0.001)$. The results suggested that activation of the CNR2 may have a certain effect in improving the infiltration of inflammatory cells in lung tissue, which may be affected by changes in the balance of Treg/Th17 cells. The cell counting result was consistent to a certain degree with that of HE staining.

\section{Effect of $\beta$-Car on STAT5 and FNK1/2 signals}

Treg and Th17 cells can be differentiated by the activity of STAT5 and Foxp3, and ROR $\gamma$ t, respectively. To further explore the specific mechanism of how the CNR2 changes Treg/Th17 balance, the expression level of STAT5, an essential factor affecting Treg cell differentiation in lung tissue, was detected by qPCR and WB analysis. The results demonstrated that the expression of STAT5 was higher in Asthma mice than Control mice $(\mathrm{P}<0.001$; Figure $2 A)$. $\beta$-Car activated the CNR2 and induced a continuously increased expression of STAT5 $(\mathrm{P}<0.001)$, while CMD178 and SR144528 both significantly inhibited the expression of STAT5 mRNA $(\mathrm{P}<0.001 ;$ Figure $2 A)$. The result revealed a positive regulatory effect of the CNR2 on the Treg/Th17 balance through regulation of STAT5. We also verified the expression of FOXP3 and ROR $\gamma \mathrm{t}$, which are the cytokines secreted by Treg and Th17, respectively. The expression trend of FOXP3 in the comparison groups was consistent with that of STAT5, and they were opposite to that of ROR $\gamma t$ in the Asthma + $\beta$-Car, and Asthma + $\beta$-Car + SR144528 groups (Figure 2B,C). This result also verified that the CNR2 agonist $\beta$-Car changed the balance of Treg/Th17.

As observed in Figure 2D, the protein expression trend of CNR2, ROR $\gamma \mathrm{t}$, and FOXP3 in the comparison groups analyzed by WB was consistent with the qPCR analysis. Moreover, p-STAT5 was also regulated by activation of the CNR2. As reported, the CNR2 can regulate the downstream JNK/c-Jun/Alox5 pathway, which also plays an important role in influencing $\mathrm{CD}^{+} \mathrm{T}$ cell differentiation $(28,29)$. To further explore the specific mechanism of the CNR2 in regulating STAT5, the expression levels of JNK1/2, p-JNK1/2, AP-1, and Alox-5 were assessed. The protein expression levels of AP-1, and Alox 5 were consistent with that of ROR $\gamma$ t, while p-JNK1/2 had the opposite expression. In summary, we concluded that the CNR2 activated the JNK/c-Jun/Alox5 pathway, which further promotes the expression of AP-1, and then cooperates with STATA3 to promote the expression of FOXP3. As expected, CMD178 and SR144528 blocked the JNK/c-Jun/ Alox 5 pathway. Furthermore, the immunohistochemical results showed that the CNR2 was mainly expressed in the nucleus, and showed brown or yellowish-brown, which was significantly increased in Asthma and Asthma $+\beta$-Car mice (Figure $3 A, B, C$ ). The $\beta$-Car antagonist and Treg inhibitor reduced the CNR2 expression (Figure 3D,E).

\section{Effect of $\beta$-Car on the differentiation of $C D 4^{+} T$ cells}

To further confirm the role of $\beta$-Car in regulating the 
A
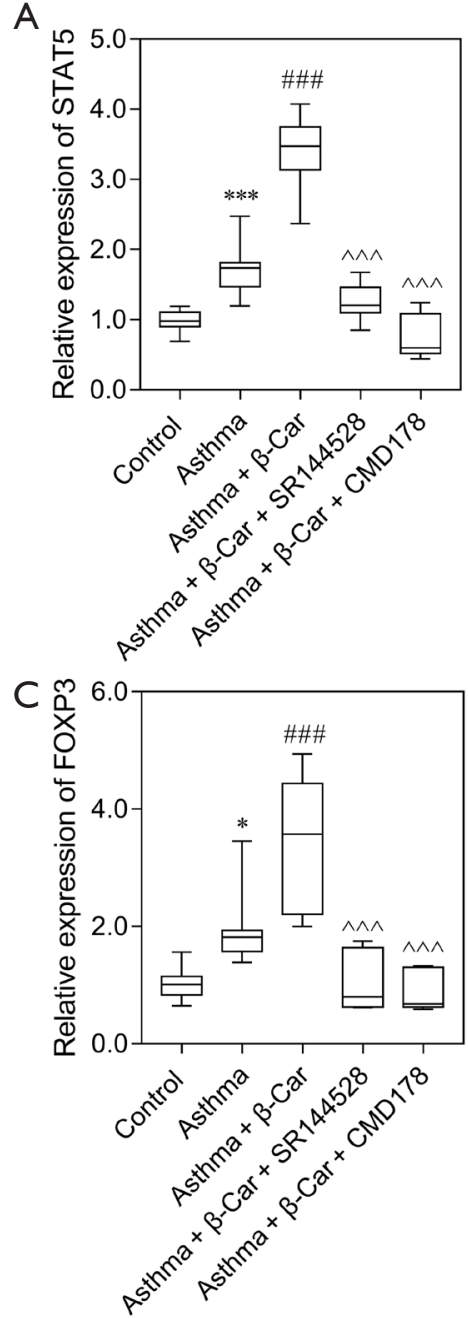

B

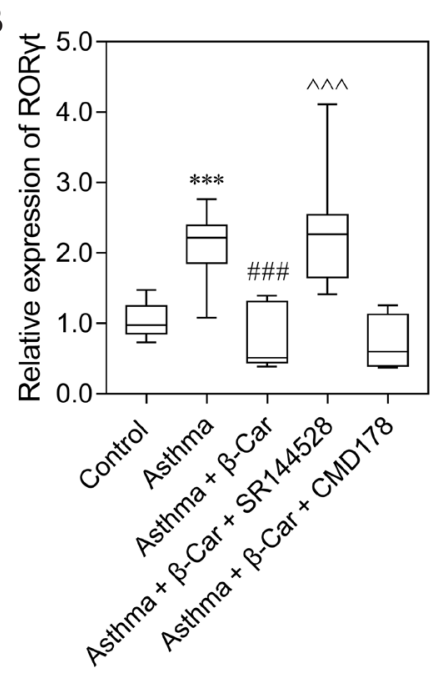

D

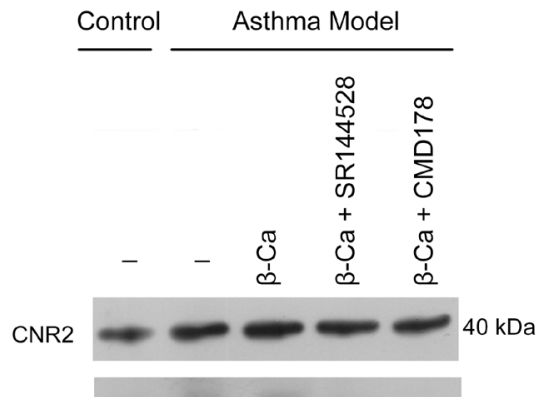

p-STAT5 (Y694)

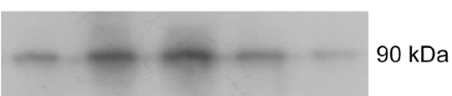

RORyt

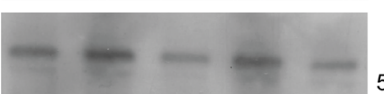

$58 \mathrm{kDa}$

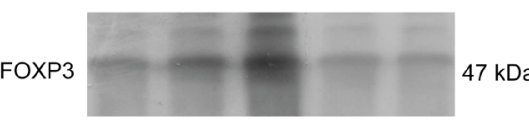

JNK1/2

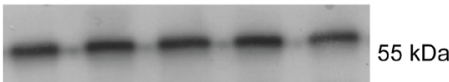

$55 \mathrm{kDa}$

p-JNK1/2 (T183 + Y185)

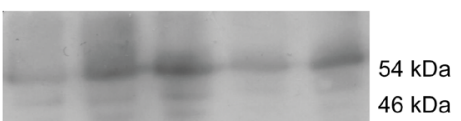

AP-1

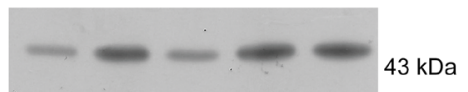

Alox5

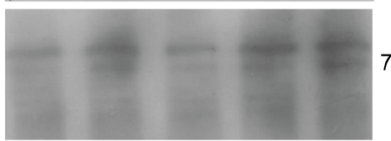

$78 \mathrm{kDa}$

GAPDH

$37 \mathrm{kDa}$

Figure 2 qPCR and WB analysis of STAT5 and JNK1/2 signaling. (A,B,C) qPCR analysis of gene expression levels of STAT5, ROR $\gamma \mathrm{t}$, and FOXP3. (D) WB analysis of protein expression levels of CNR2, p-STAT5, ROR $\gamma$ t, FOXP3, JNK1/2, p-JNK1/2(T183 + Y185), AP-1, and Alox5. Each experiment was triplicate. ${ }^{*} \mathrm{P}<0.05,{ }^{* * *} \mathrm{P}<0.001$ vs. Control group; ${ }^{\# \# \#} \mathrm{P}<0.001$ vs. Asthma group; ${ }^{\wedge \wedge} \mathrm{P}<0.001$ vs. Asthma $+\beta-\mathrm{Car}$ group. qPCR, quantitative polymerase chain reaction; $\mathrm{WB}$, western blot.

Treg/Th17 balance, directed differentiation of Treg and Th17 cells was used to analyze the mechanism in vitro. As shown by the flow cytometric results in Figure 4, the proportion of $\mathrm{CD}_{25} 5^{+}$and $\mathrm{FOXP} 3^{+}$cells in the Treg directed-differentiation group (Treg-DD) was higher than in the Control group $(\mathrm{P}<0.001$; Figure $4 A, B)$, while

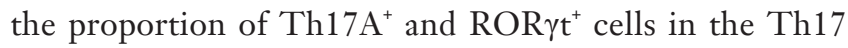
directed-differentiation group (Th17-DD) was lower $(\mathrm{P}<0.001$; Figure $4 C, D)$, indicating in vitro induction promoting directed cell differentiation. The $\beta$-Car intervention further significantly promoted the increase in the proportion of $\mathrm{FOXP}^{+}$cells $(\mathrm{P}<0.05)$ and decreased

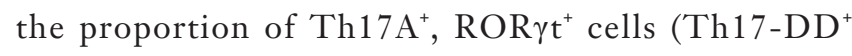
$\beta$-Car; $\mathrm{P}<0.001)$. This result indicated that $\beta$-Car can promote the orientation of Treg cells after activating the CNR2, but has a certain inhibitory effect on the targeted differentiation of Th17 cells. Also, SR144528 interfered with the effect of $\beta$-Car. To sum up, the experiment proved the effect of CNR2 activation on the balance of Treg/ Th17 cells. The inflammatory cytokines IL-10, IL-17A, and IL-22 in the cells of Control, Treg-DD, Treg-DD + $\beta$-Car, Treg-DD + $\beta$-Car + SR144528, Th17-DD, Th17 + $\beta$-Car, and Th17-DD + $\beta$-Car + SR144528 were assessed and shown in Figure $5 A, B, C$. Compared with the Control 

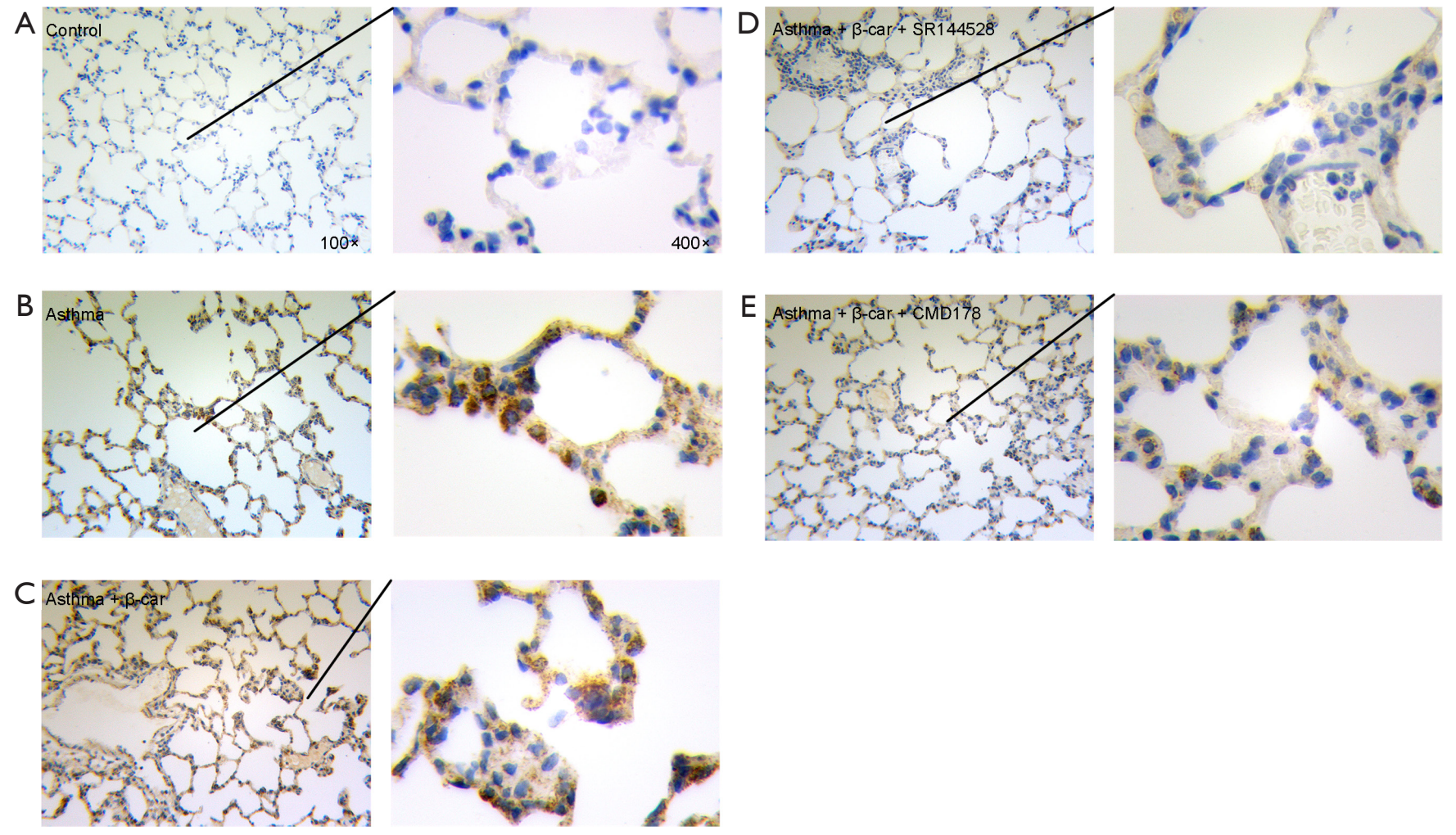

Figure 3 Expression of CNR2 in lung tissue was induced by $\beta$-Car. Expression of CNR2 (100x and 400x) in right lung tissue from (A) Control group, (B) Asthma group, (C) Asthma $+\beta$-Car group, (D) Asthma $+\beta$-Car + SR144528 group and (E) Asthma $+\beta$-Car + CMD178 group was showed by immunohistochemical staining. $\beta$-Car, $\beta$-caryophyllene; CNR2, cannabinoid receptor 2.

group, the concentration of IL-10 in the Treg-DD group was significantly increased, while IL-17A and IL-22 were significantly decreased $(\mathrm{P}<0.001)$. In the Th17-DD group, the concentration of IL-10 was significantly decreased, but IL-17A and IL-22A were significantly increased compared with the Control. $\beta$-Car promoted the release of IL-10 and significantly inhibited the release of IL-17A. As expected, SR144528 had a significant blocking effect on $\beta$-Car. Combined, we can conclude that the CNR2 promoted the cells differentiating to Treg but not Th17, which increased the Treg/Th17 proportion.

Furthermore, the mRNA and protein expression levels of CNR2, STAT5, ROR $\mathrm{T}$, and FOXP3 in cells from the Control, Treg-DD, Treg-DD + $\beta$-Car, Treg-DD + $\beta$-Car + SR144528, Th17-DD, Th17 + $\beta$-Car, and Th17-DD + $\beta-$ Car + SR144528 groups were assessed. The expression level of CNR2 was significantly increased in cells treated with induction compared with Control group $(\mathrm{P}<0.001)$, but showed no significant differences with other treatments (Figure 5D), indicating expression unaffected by $\beta$-Car and
SR144528. The expression level of STAT5 was significantly increased in the Treg-DD group $(\mathrm{P}<0.001)$ compared with the Control group. Compared with the Treg-DD group, the expression level of STAT5 was significantly promoted by the $\beta$-Car intervention $(\mathrm{P}<0.001)$, but significantly decreased by $\mathrm{SR} 144528(\mathrm{P}<0.001)$, suggesting a promoting role of $\beta$-Car and blocking role of SR144528 on the expression of STAT5. $\beta$-Car administration had a significant positive influence on the expression of STATS in the Th17 directeddifferentiation group, and SR144528 blocked its effect $(\mathrm{P}<0.001$; Figure $5 E)$. The expression trends of ROR $\gamma t$ and $F O X P 3$ were consistent with those shown by flow cytometry (Figure 5F,G).

The protein expression level of CNR2 was consistent with that of the qPCR analysis, which was significantly increased with the induction of Treg/Th17, $\beta$-Car and SR144528 (Figure 5H). The protein expression levels of p-STAT5, ROR $\gamma$ t, and FOXP3 were consistent with those from qPCR analysis and flow cytometry. Nevertheless, the protein levels of $\mathrm{p}-\mathrm{JNK}$ and AP-1 increased under the 
A
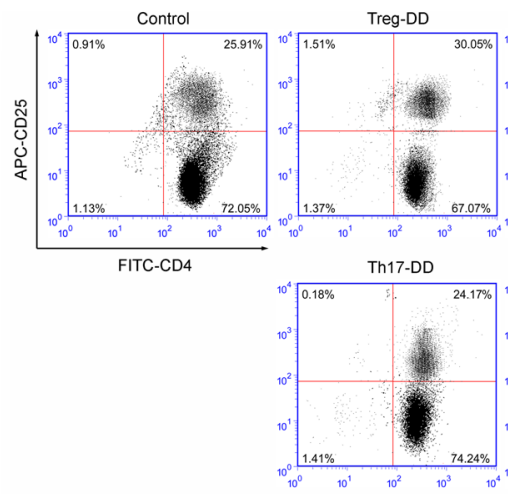

B
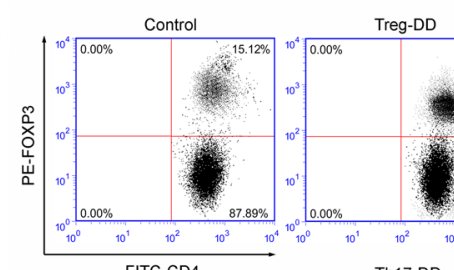
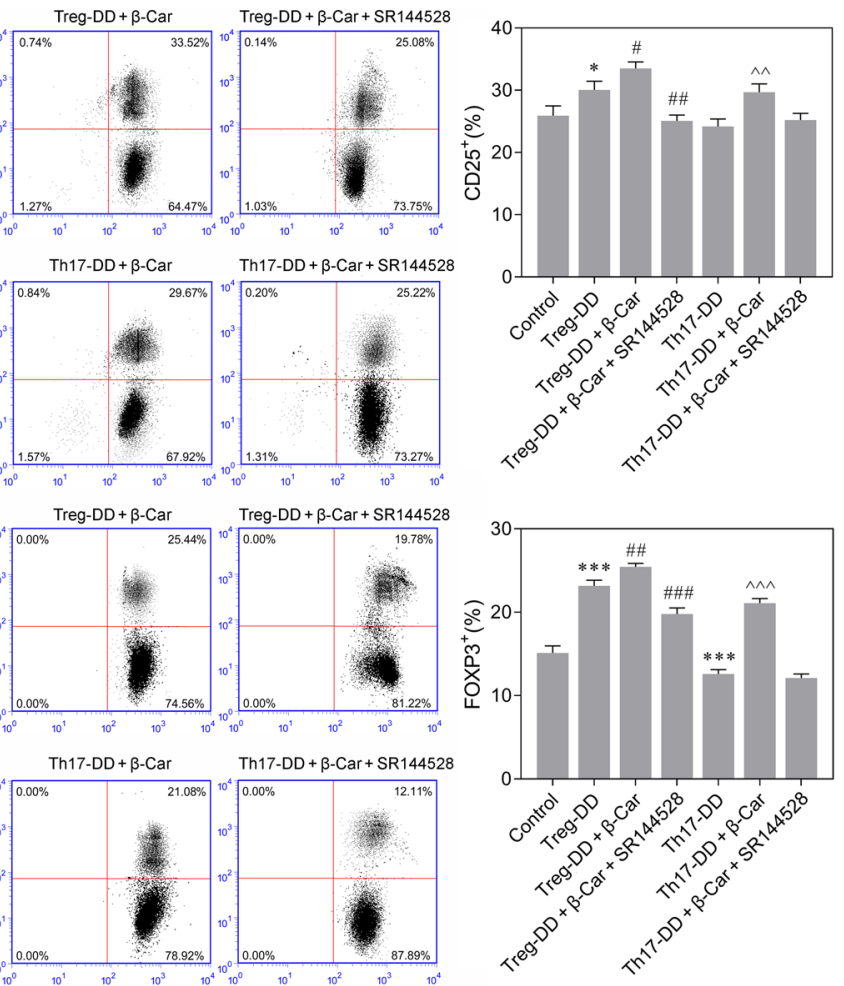

C
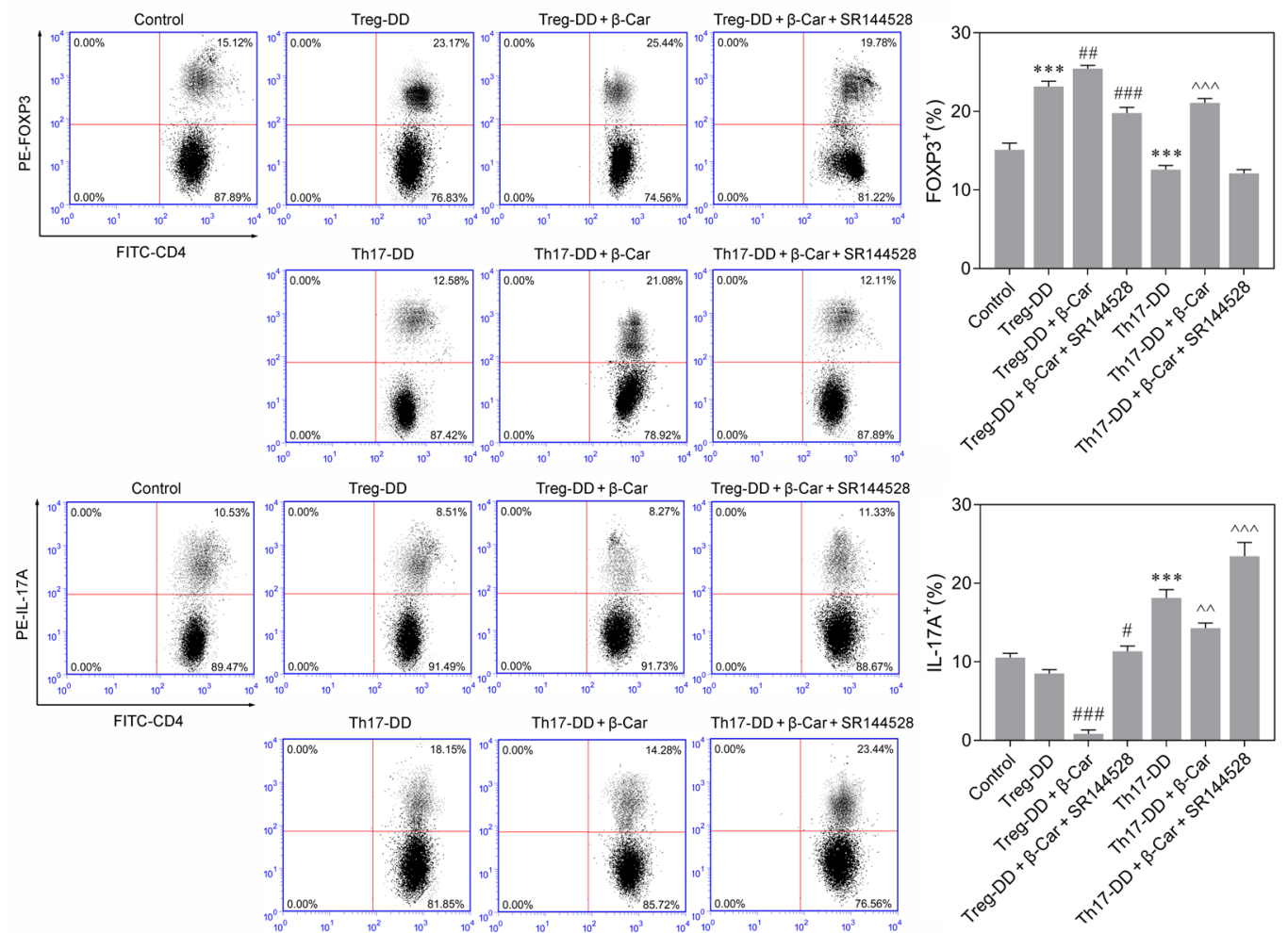

$\mathrm{D}$
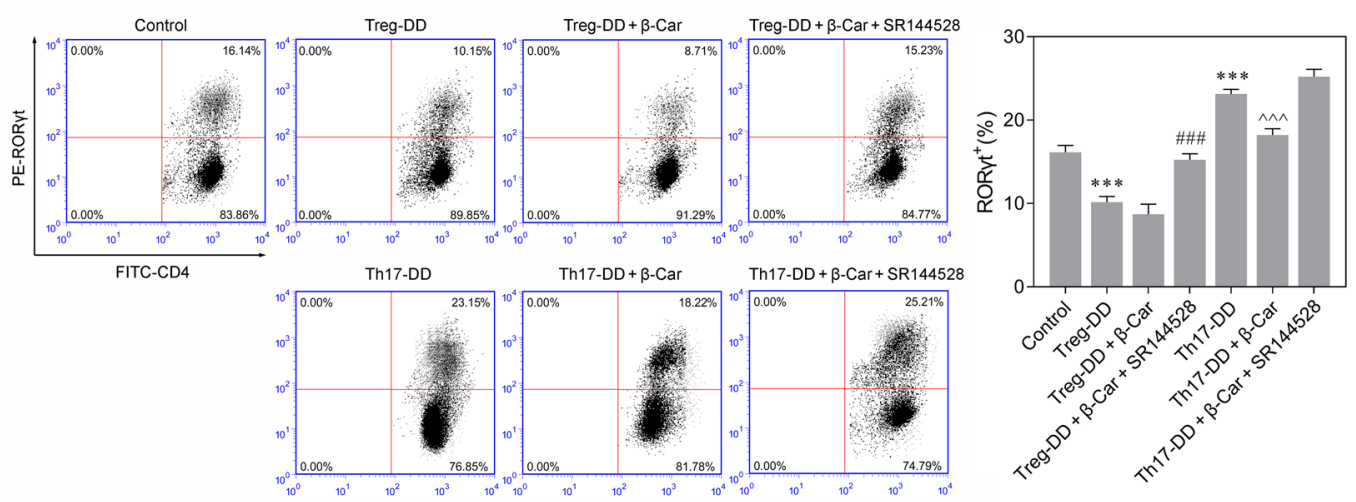

Figure 4 Influence of $\beta$-Car on direct differentiation of Treg/Th17 in vitro. $\mathrm{CD} 4^{+} \mathrm{T}$ cells were directly differentiated into Treg or Th17 by induction. Flow cytometry showed the ratio of CD25/CD4 (A), FOXP3/CD4 (B), IL-17A/CD4 (C), and ROR $\gamma t / C D 4$ (D) expressed in cells. Each experiment was triplicate. ${ }^{*} \mathrm{P}<0.05,{ }^{* * *} \mathrm{P}<0.001$ vs. Control group; ${ }^{\#} \mathrm{P}<0.05,{ }^{\# \#} \mathrm{P}<0.01,{ }^{{ }^{* \prime \prime}} \mathrm{P}<0.001$ vs. Treg-DD group; ${ }^{\wedge} \mathrm{P}<0.01$, ${ }^{\wedge \wedge} \mathrm{P}<0.001$ vs. Th17-DD group. DD, direct differentiation; IL, interleukin; Treg, regulatory $\mathrm{T}$ cell. 
A

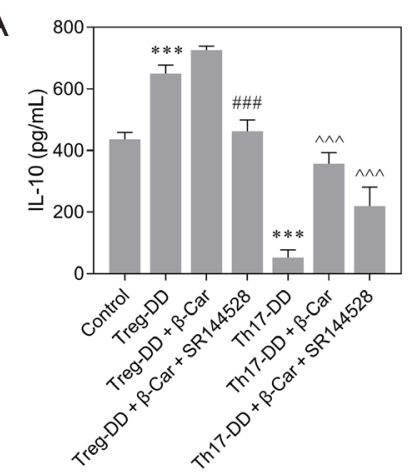

C

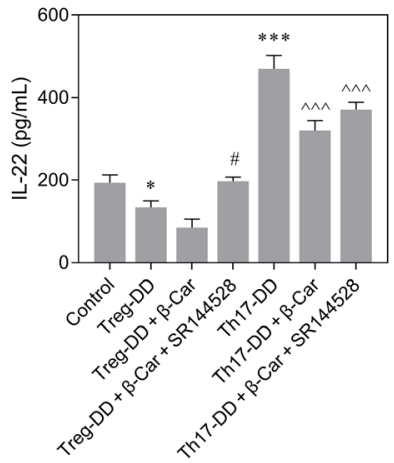

D

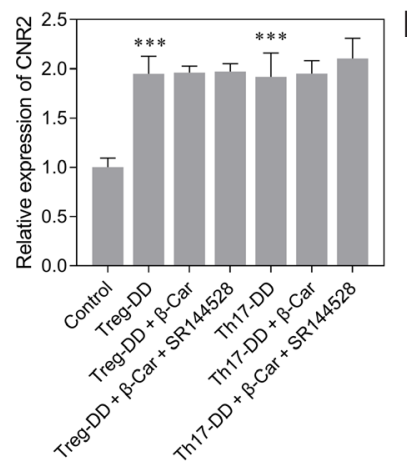

$\mathrm{F}$

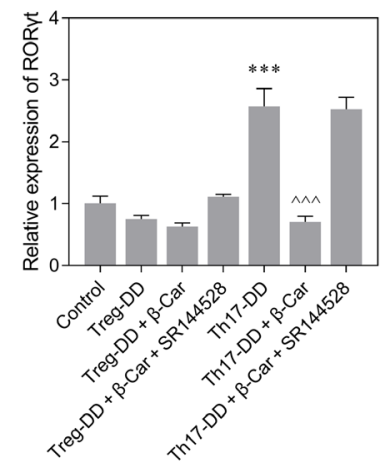

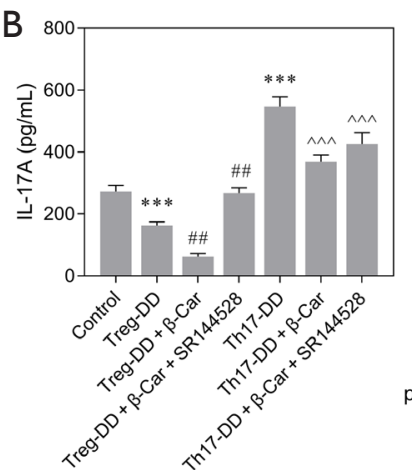

$\mathrm{H}$ $\underline{\text { Control }}+$ Treg-DD $\longrightarrow$ Th17-DD

-STAT5 (Y694)

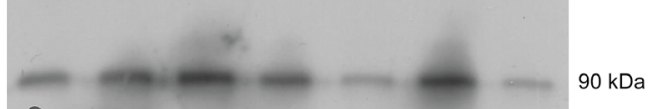

RORyt

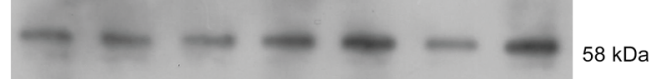

p-JNK1/2 (T183+ Y185)

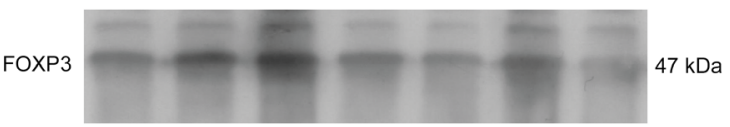

JNK1/2

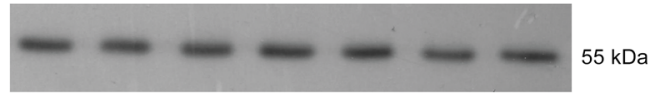

$(183+Y 185)$
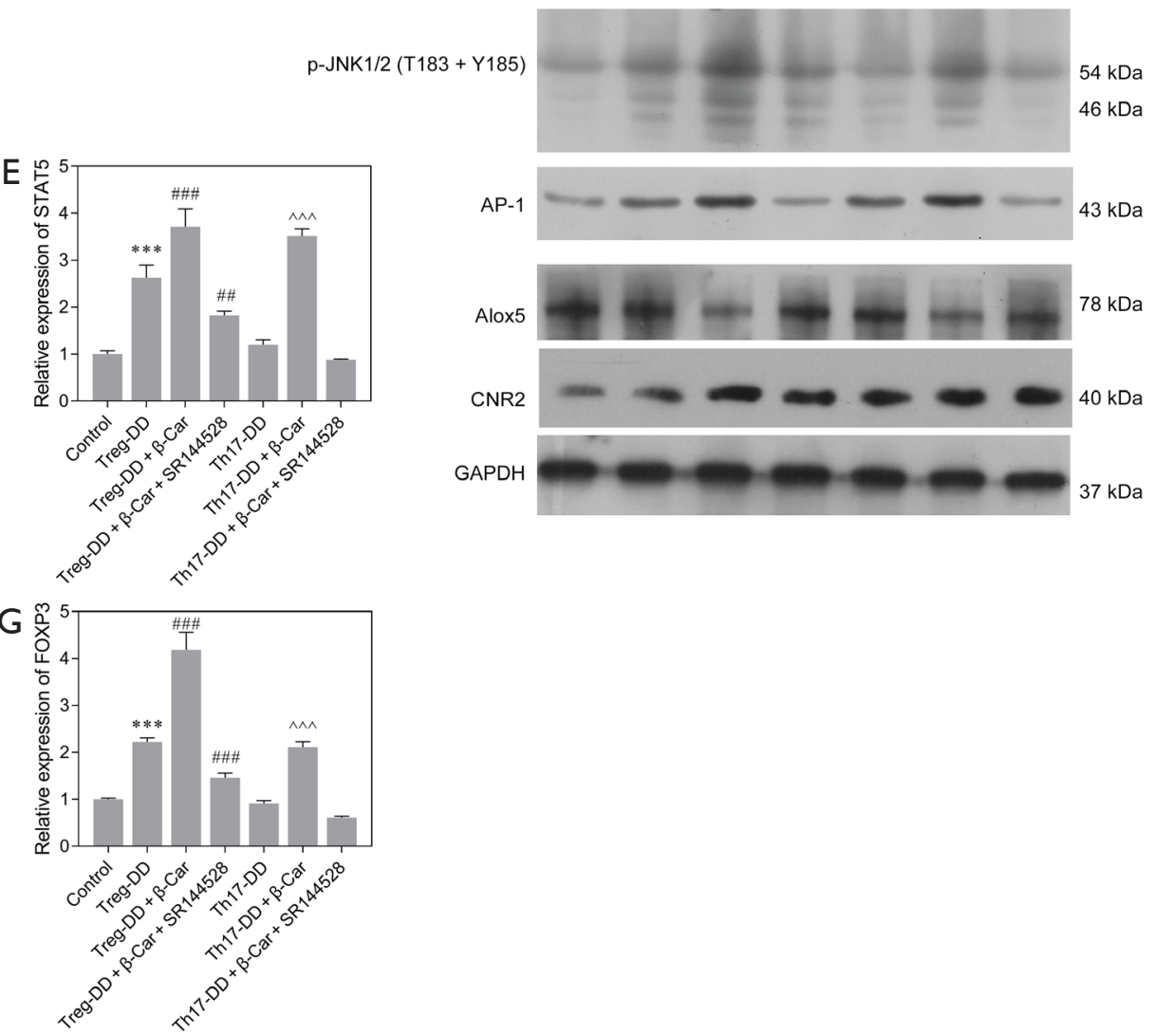

Figure 5 Activation of CNR2 promoted Treg differentiation and inhibited Th17 differentiation by regulating STAT5 and JNK1/2 signaling. (A,B,C) Level of cytokines secreted by Treg (IL-10) and Th17 (IL-17A and IL-22) as assessed by ELISA. (D,E,F,G) Expression of CNR2, STAT5, ROR $\gamma$ t, and FOXP3 as detected by RT-qPCR. (H) WB analysis shows the protein levels of CNR2, p-STAT5, ROR, FOXP3, JNK1/2, p-JNK1/2(T183 + Y185), AP-1, and Alox5. Each experiment was triplicate. ${ }^{*} \mathrm{P}<0.05$, ${ }^{* *} \mathrm{P}<0.001$ vs. Control group; ${ }^{\#} \mathrm{P}<0.05,{ }^{\# \#} \mathrm{P}<0.01$,

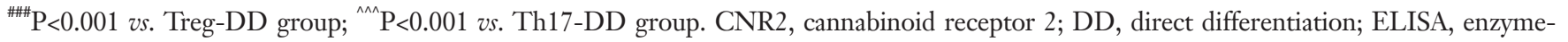
linked immunosorbent assay; RT-qPCR, real-time quantitative polymerase chain reaction; Treg, regulatory T cell; WB, western blot. 

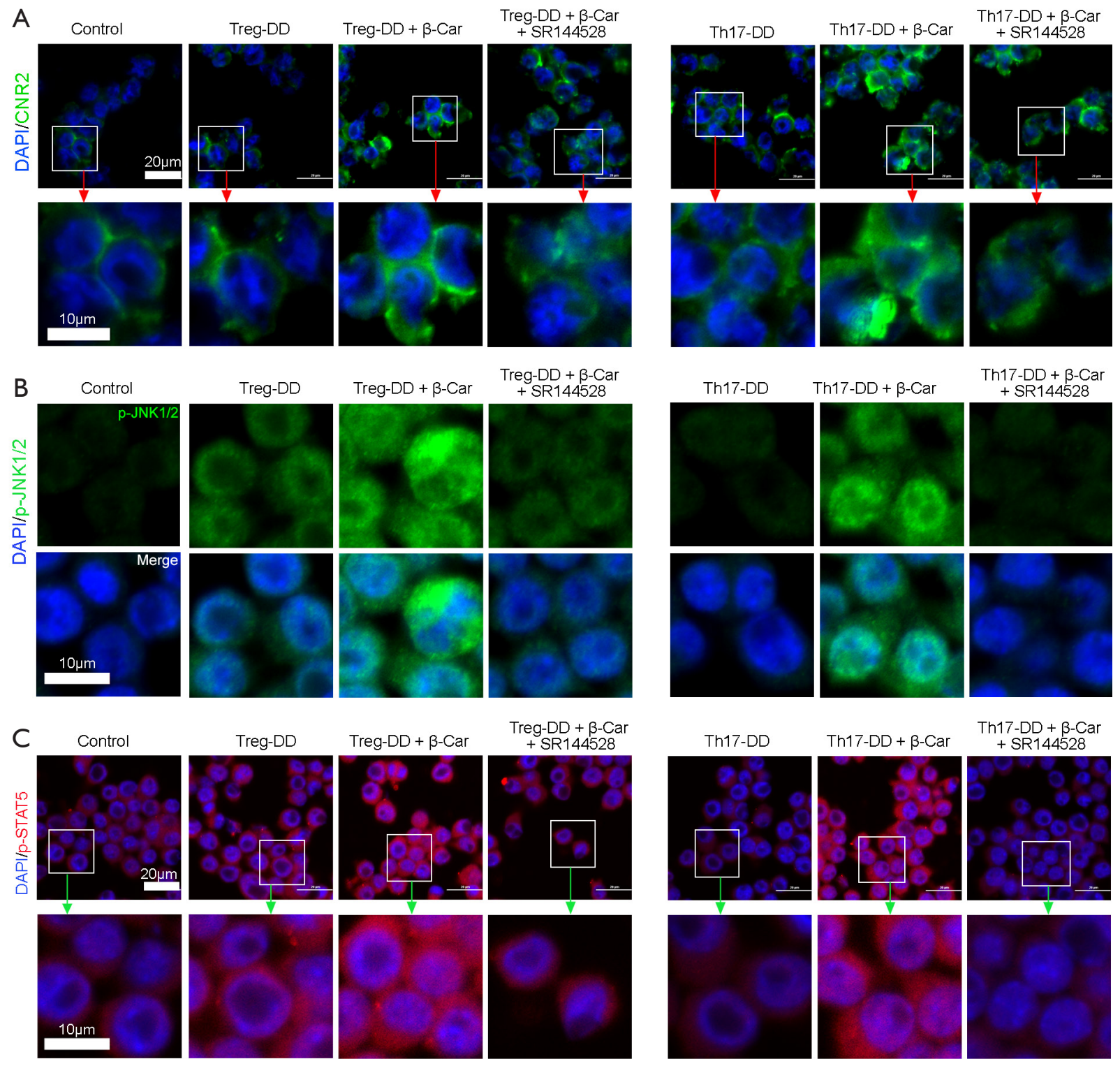

Th17-DD + $\beta$-Car

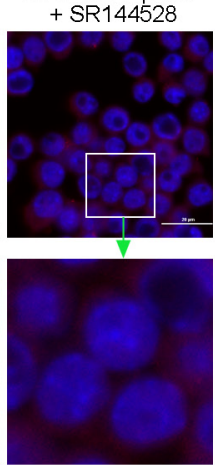

Figure 6 Activation of CNR2 promoted phosphorylation of STAT5 and JNK1/2. Immunofluorescence was used to detect the protein level of CNR2 (A), p-JNK1/2 (B) and p-STAT5 (C) in cells (scale bar: 20 or $10 \mu \mathrm{m}$ ). blue, DAPI; green, p-JNK1/2 and CNR2; red, p-STAT5; CNR2, cannabinoid receptor 2; DD, direct differentiation.

influence of $\beta$-Car, but not other treatments. WB analysis revealed that activation of the CNR2 might promote the differentiation of $\mathrm{T}$ cells into Treg cells through the JNK/ c-Jun/Alox 5 pathway. In summary, qPCR and WB analysis revealed that $\beta$-Car promoted the gene expression of STAT5 and FOXP3 (Treg) and suppressed that of ROR $\gamma \mathrm{t}$ (Th17), possibly through JNK/c-Jun/Alox5 pathway.

As shown in Figure 6A,B,C, the protein expression levels of CNR2, p-JAK1/2, and p-STAT5 in the Treg-DD group were significantly higher than in the Control group. $\beta$-Car administration significantly elevated the expression levels of CNR2, p-JAK1/2, and p-STAT5, in both the Treg and Th17 direct-differentiation groups. The result for p-JAK1/2 was consistent with that of WB analysis.

\section{Discussion}

The high incidence of neutrophilic asthma and difficulty 
with treatment have become a global problem. It is known that an imbalance of Treg/Th17 cells exists in asthma, so increasing the levels of Treg, reducing those of Th17, thus increasing the proportion of Treg to Th17 has potential for the treatment of neutrophilic asthma. In this study, we used a tobacco smoke-exposed OVA-sensitized asthmatic mice model to study the effect of CNR2 activation on the occurrence of neutrophilic asthma. At the cellular level, we also studied the molecular mechanism of CNR2 activation in regulating the differentiation of $\mathrm{CD}^{+} \mathrm{T}$ cells and affecting the ratio of Treg/Th17. We concluded the following: (I) the selective CNR2 agonist $\beta$-Car ameliorated asthma in mice; (II) $\beta$-Car decreased immune cell accumulation in the neutrophilic asthma mice; (III) $\beta$-Car prompted $\mathrm{CD}^{+}$differentiation into Treg cells but inhibited Th17 cells in vitro; and (IV) $\beta$-Car regulated the Treg/Th17 balance and relieved neutrophilic asthma possibly through the JNK/c-Jun/Alox5 pathway.

Inflammation, the response of the immune system against infection and injuries, is the earliest and complex biological reaction (30). Asthma is a chronic inflammatory disease of the airways that involves inflammatory cells such as eosinophils, neutrophils, mast cells, and T lymphocytes. It is caused by hypersecretion of airway mucus, airway hyperresponsiveness (AHR), and airway remodeling (31). In the present study, the numbers of inflammatory cells, including lymphocytes, eosinophils, and neutrophils, were significantly increased in the mice subjected to a cigarette smoke environment and induced with neutrophilic asthma than Control mice, which proved the influence of cigarette smoke on enhancing inflammation in neutrophilic asthma. Therefore, relieving inflammation is the main way of treating neutrophilic asthma.

$\beta$-Car is a selective CB2 agonist, which has antiinflammatory and antioxidant effects by activating the CNR2 (30). $\beta$-Car elicits a full agonist action on the CNR2, and activates CD14/TLR4/MD2, reducing the immune inflammatory processes, and thus exhibiting synergy with $\mu$-opioid receptor-dependent pathways (32). It acts as a G-protein coupled receptor, thus representing an important therapeutic target in several diseases. Not only its antiinflammatory activity, it also has other pharmacological activities, including neuroprotective, gastroprotective, antioxidant, hepatoprotective, immune-modulator etc. In recent years, $\beta$-Car at low concentration exerted promising protective effects that could be considered for the treatment of neurodegenerative disorders such as multiple sclerosis (33). He et al. (34) proposed that $\beta$-Car could be a potential new pharmacotherapy for cigarette smoking cessation because of its significant anti-nicotine effects via both CB2 and non-CB2 receptor mechanisms. In the present study, $\beta$-Car improved the infiltration of inflammatory cells in the lung tissue exposed to cigarette smoking, and decreased cell accumulation in the neutrophilic asthmatic mice. Moreover, the in vivo experiment demonstrated that $\beta$-Car increased the proportion of Treg to Th17 cells.

Treg and Th17 cells have opposing responses to inflammation, with Treg having an immunosuppressive capacity and Th17 cells contributing to the inflammatory response. Hence, the lack of Treg cells and abundant Th17 cells promote the immunological pathogenesis of asthma $(25,35)$. Studies have demonstrated that Treg and Th17 cells play an essential role in the pathogenesis of asthma (36-39). Several studies have illustrated the importance of the Treg/Th17 balance in regulating inflammation and asthma. Wang et al. (25) confirmed the existence of an imbalance of Treg/Th17 cells in asthma but results were only limited to peripheral blood. Studies have found that the proportion of Treg in the lungs of patients with allergic asthma is reduced, and that immunosuppressive activity is reduced (40). Moreover, animal experiments have confirmed that Treg mediate immunosuppressive responses by secreting immunosuppressive cytokines such as IL-10 and TGF- $\beta$, and reverse AHR, inflammation, and airway remodeling $(41,42)$. Liu et al. (43) found that the ratio of Th2 to Th17 was decreased and the ratios of IL- $1 \alpha$, IL- 6 , and IL-8 were increased in the BALF of patients with neutrophilic asthma. Wang et al. (44) reported that the traditional Chinese medicine "Yupingfeng Powder" can inhibit airway inflammation in OVA-induced asthmatic mice by regulating the balance between Th17 and Treg cells. In the present study, we found that $\beta$-Car promoted $\mathrm{CD}^{+}$differentiation into Treg cells but inhibited Th17 cells, which promoted the proportion of Treg to Th17, thus alleviating neutrophilic asthma.

Not only $\beta$-Car, some other CNR2-selective agonists might also regulate the Treg/Th17 balance. A previous study had found that the biologically active component of Delta(9)-tetrahydrocannabinol cannabinoids $(\triangle 9-\mathrm{THC})$ can upregulate FOXP3 + Treg cells in the liver and inhibit concanavalin A (Con-A)-induced hepatitis in mice, depending on both CB1 and CB2 agonists (45). In the in vitro study by Robinson et al. (46), the mixed lymphocyte reaction (MLR) revealed that the CNR2 agonist O-1966 activated Treg and promote increased 
IL-10 secretion in the MLR culture supernatant. It was also found that $\mathrm{CD}^{+} \mathrm{T}$ cells were downregulated in the wild-type MLR, but the expression of $\mathrm{CD}^{+}{ }^{+} \mathrm{T}$ cells in MLR with CNR2 knock-out did not change, suggesting a promoting role of the CNR2 on the proportion and activity of Treg cells. In their study of experimental autoimmune encephalomyelitis (EAE), Kong et al. (47) found that the CNR2 selective agonist GP1a treatment of EAE mice inhibited the expression of ROR $\gamma \mathrm{t}$, and IL-17 and Th17 differentiation, and enhanced the expression of FOXP3 and IL-10 and Treg differentiation $(48,49)$, which suggested that CNR2 agonist activation may directly promote Treg differentiation, reduce Th17 differentiation, and affect the ratio and activity of Treg/Th17.

As reported, the CNR2 can regulate the downstream JNK/c-Jun/Alox5 pathway, which also plays a critical role in influencing $\mathrm{CD}^{+} \mathrm{T}$ cell differentiation $(28,29)$. In the present study, the genes involved in the JNK/c-Jun/Alox 5 pathway were dysregulated with $\beta$-Car administration, suggesting that $\beta$-Car regulates the Treg/Th17 balance and can relieve neutrophilic asthma, possibly through the JNK/ c-Jun/Alox5 pathway.

\section{Conclusions}

In summary, the present study revealed the mechanism of the CNR2 agonist $\beta$-Car in regulating the Treg/Th17 balance in neutrophilic asthma. $\beta$-Car promoted $\mathrm{CD} 4^{+}$ $\mathrm{T}$ cell differentiation into Treg cells but not Th17 cells, thus increasing the proportion of Treg to Th17, relieving neutrophilic asthma. Moreover, it acted through the JNK/c-Jun/Alox5 pathway. This research provides a solid foundation for clinical application.

\section{Acknowledgments}

The authors thank the staff of the Public Laboratory of Hainan General Hospital for advice and use of experimental instruments.

Funding: This research is supported by the grant from the National Natural Science Foundation of China (No. 81860007).

\section{Footnote}

Reporting Checklist: The authors have completed the ARRIVE reporting checklist. Available at https://dx.doi. org/10.21037/atm-21-2778
Data Sharing Statement: Available at https://dx.doi. org/10.21037/atm-21-2778

Conflicts of Interest: All authors have completed the ICMJE uniform disclosure form (available at https://dx.doi. org/10.21037/atm-21-2778). The authors have no conflicts of interest to declare.

Ethical Statement: The authors are accountable for all aspects of the work in ensuring that questions related to the accuracy or integrity of any part of the work are appropriately investigated and resolved. Experiments were performed under a project license (No.: 202005-08) granted by institutional Ethics Committee Board of Hainan General Hospital, in compliance with international ethical guidelines and the National Institutes of Health Guide concerning the Care and Use of Laboratory Animals.

Open Access Statement: This is an Open Access article distributed in accordance with the Creative Commons Attribution-NonCommercial-NoDerivs 4.0 International License (CC BY-NC-ND 4.0), which permits the noncommercial replication and distribution of the article with the strict proviso that no changes or edits are made and the original work is properly cited (including links to both the formal publication through the relevant DOI and the license). See: https://creativecommons.org/licenses/by-nc-nd/4.0/.

\section{References}

1. Jacinto T, Malinovchi A, Janson C, et al. Effect of cigarette smoke exposure on exhaled nitric oxide and its relation to asthma and hay fever in adult NHANES subjects. Eur Respiratory J 2015;46:PA4000.

2. Olin JT, Wechsler ME. Asthma: pathogenesis and novel drugs for treatment. Bmj 2014;349:g5517.

3. Pelaia G, Vatrella A, Busceti MT, et al. Cellular mechanisms underlying eosinophilic and neutrophilic airway inflammation in asthma. Mediators Inflamm 2015;2015:879783.

4. Ciepiela O, Ostafin M, Demkow U. Neutrophils in asthma-a review. Respir Physiol Neurobiol 2015;209:13-6.

5. Polosa R, Knoke JD, Russo C, et al. Cigarette smoking is associated with a greater risk of incident asthma in allergic rhinitis. J Allergy Clin Immunol 2008;121:1428-34.

6. Kim DY, Kwon EY, Hong GU, et al. Cigarette smoke exacerbates mouse allergic asthma through Smad proteins 
expressed in mast cells. Respir Res 2011;12:49.

7. Aoshiba K, Nagai A. Differences in airway remodeling between asthma and chronic obstructive pulmonary disease. Clin Rev Allergy Immunol 2004;27:35-43.

8. Choi IS. Immune tolerance by induced regulatory $\mathrm{T}$ cells in asthma. Allergy Asthma Immunol Res 2012;4:113-5.

9. Eisenstein EM, Williams CB. The T reg/Th17 Cell Balance: A New Paradigm for Autoimmunity. Pediatr Res 2009;65:26R-31R.

10. Talaat RM, Mohamed SF, Bassyouni IH, et al. Th1/ Th2/Th17/Treg cytokine imbalance in systemic lupus erythematosus (SLE) patients: Correlation with disease activity. Cytokine 2015;72:146-53.

11. Kong QF, Sun B, Bai SS, et al. Administration of bone marrow stromal cells ameliorates experimental autoimmune myasthenia gravis by altering the balance of Th1/Th2/Th17/Treg cell subsets through the secretion of TGF- $\beta$. J Neuroimmunol 2009;207:83-91.

12. Zou XL, Chen ZG, Zhang TT, et al. Th17/Treg homeostasis, but not Th1/Th2 homeostasis, is implicated in exacerbation of human bronchial asthma. Ther Clin Risk Manag 2018;14:1627.

13. Howlett AC, Breivogel CS, Childers SR, et al. Cannabinoid physiology and pharmacology: 30 years of progress. Neuropharmacology 2004;47:345-58.

14. Accordini S, Calciano L, Bombieri C, et al. Inflammationrelated genes, peripheral blood eosinophil (EOS) and neutrophil (NEU) count, and lung function in adult asthma. Eur Respiratory J 2015;46:PA1234.

15. Wu SQ, Wang GL, Li LY, et al. Effects of microRNA-21 on the interleukin 12/signal transducer and activator of transcription 4 signaling pathway in asthmatic mice. Cent Eur J Immunol 2014;39:40.

16. Ferrini ME, Hong S, Stierle A, et al. CB 2 receptors regulate natural killer cells that limit allergic airway inflammation in a murine model of asthma. Allergy 2017;72:937-47.

17. Parlar A, Arslan S. CB2 Agonist (AM1241) Improving Effect on Ovalbumin-Induced Asthma in Rats. Iran J Pharm Res 2020;19:3-17.

18. Turcotte C, Blanchet MR, Laviolette M, et al. Impact of cannabis, cannabinoids, and endocannabinoids in the lungs. Front Pharmacol 2016;7:317.

19. Wang LL, Zhao R, Li JY, et al. Pharmacological activation of cannabinoid 2 receptor attenuates inflammation, fibrogenesis, and promotes re-epithelialization during skin wound healing. Eur J Pharmacol 2016;786:128-36.

20. Lowin T, Pongratz G, Straub RH. The synthetic cannabinoid WIN55, 212-2 mesylate decreases the production of inflammatory mediators in rheumatoid arthritis synovial fibroblasts by activating CB 2, TRPV1, TRPA1 and yet unidentified receptor targets. J Inflamm (Lond) 2016;13:15.

21. Lowin T, Straub RH. Cannabinoid-based drugs targeting CB 1 and TRPV1, the sympathetic nervous system, and arthritis. Arthritis Res Ther 2015;17:226.

22. Fukuda H, Abe T, Yoshihara S. The cannabinoid receptor agonist WIN 55,212-2 inhibits antigen-induced plasma extravasation in guinea pig airways. Int Arch Allergy Immunol 2010;152:295-300.

23. Ci X, Chu X, Wei M, et al. Different effects of farrerol on an OVA-induced allergic asthma and LPS-induced acute lung injury. PLoS One 2012; 7:e34634.

24. Hwang YH, Hong SG, Mun SK, et al. The protective effects of astaxanthin on the OVA-induced asthma mice model. Molecules 2017;22:2019.

25. Wang L, Wan H, Tang W, et al. Critical roles of adenosine A2A receptor in regulating the balance of Treg/Th17 cells in allergic asthma. Clin Respir J 2018;12:149-57.

26. Rego SL, Zakhem E, Orlando G, et al. Bioengineered human pyloric sphincters using autologous smooth muscle and neural progenitor cells. Tissue Eng Part A 2016;22:151-60.

27. Rego SL, Helms RS, Dréau D. Breast tumor cell TACEshed MCSF promotes pro-angiogenic macrophages through NF- $\kappa \mathrm{B}$ signaling. Angiogenesis 2014;17:573-85.

28. Correa F, Hernangómez M, Mestre L, et al. Anandamide enhances IL-10 production in activated microglia by targeting CB2 receptors: Roles of ERK1/2, JNK, and NF«B. Glia 2010;58:135-47.

29. Liu YJ, Fan HB, Jin Y, et al. Cannabinoid receptor 2 suppresses leukocyte inflammatory migration by modulating the JNK/c-Jun/Alox5 pathway. J Biol Chem 2013;288:13551-62.

30. Askari VR, Shafiee-Nick R. The protective effects of $\beta$-caryophyllene on LPS-induced primary microglia M1/M2 imbalance: A mechanistic evaluation. Life Sci 2019;219:40-73.

31. Nakagome K, Nagata M. Pathogenesis of airway inflammation in bronchial asthma. Auris Nasus Larynx 2011;38:555-63.

32. Sharma C, Al Kaabi JM, Nurulain SM, et al. Polypharmacological properties and therapeutic potential of $\beta$-caryophyllene: a dietary phytocannabinoid of pharmaceutical promise. Curr Pharm Des 2016;22:3237-64.

33. Askari VR, Shafiee-Nick R. Promising neuroprotective 
effects of $\beta$-caryophyllene against LPS-induced oligodendrocyte toxicity: A mechanistic study. Biochem Pharmacol 2019;159:154-71.

34. He Y, Galaj E, Bi GH, et al. $\beta$-Caryophyllene, a dietary terpenoid, inhibits nicotine taking and nicotine seeking in rodents. Br J Pharmacol 2020;177:2058-72.

35. Kearley J, Barker JE, Robinson DS, et al. Resolution of airway inflammation and hyperreactivity after in vivo transfer of CD4+ CD25+ regulatory T cells is interleukin 10 dependent. J Exp Med 2005;202:1539-47.

36. Shi YH, Shi GC, Wan HY, et al. Coexistence of Th1/ Th2 and Th17/Treg imbalances in patients with allergic asthma. Chin Med J (Engl) 2011;124:1951-6.

37. Tao B, Ruan G, Wang D, et al. Imbalance of peripheral Th17 and regulatory $T$ Cells in children with allergic Rhinitis AND bronchial asthma. Iran J Allergy Asthma Immunol 2015;14:273-9.

38. Li MO, Wan YY, Sanjabi S, et al. Transforming growth factor- $\beta$ regulation of immune responses. Annu Rev Immunol 2006;24:99-146.

39. Wakashin H, Hirose K, Maezawa Y, et al. IL-23 and Th17 cells enhance Th2-cell-mediated eosinophilic airway inflammation in mice. Am J Respir Crit Care Med 2008;178:1023-32.

40. Hartl D, Koller B, Mehlhorn AT, et al. Quantitative and functional impairment of pulmonary CD4+ CD25hi regulatory $\mathrm{T}$ cells in pediatric asthma. J Allergy Clin Immunol 2007;119:1258-66.

41. Kearley J, Robinson DS, Lloyd CM. CD4+ CD25+ regulatory $\mathrm{T}$ cells reverse established allergic airway inflammation and prevent airway remodeling. J Allergy Clin Immunol 2008;122:617-624.e6.

42. Presser K, Schwinge D, Wegmann M, et al. Coexpression

Cite this article as: Wei C, Huang L, Zheng Y, Cai X. Selective activation of cannabinoid receptor 2 regulates Treg/ Th17 balance to ameliorate neutrophilic asthma in mice. Ann Transl Med 2021;9(12):1015. doi: 10.21037/atm-21-2778 of TGF- $\beta 1$ and IL-10 enables regulatory T cells to completely suppress airway hyperreactivity. J Immunol 2008;181:7751-8.

43. Liu LL, Li FH, Zhang Y, et al. Tangeretin has antiasthmatic effects via regulating $\mathrm{PI} 3 \mathrm{~K}$ and Notch signaling and modulating Th1/Th2/Th17 cytokine balance in neonatal asthmatic mice. Braz J Med Biol Res 2017;50:e5991.

44. Wang Z, Cai X, Pang Z, et al. Yupingfeng pulvis regulates the balance of $\mathrm{T}$ cell subsets in asthma mice. Evid Based Complement Alternat Med 2016;2016:6916353.

45. Jan TR, Farraj AK, Harkema JR, et al. Attenuation of the ovalbumin-induced allergic airway response by cannabinoid treatment in A/J mice. Toxicol Appl Pharmacol 2003;188:24-35.

46. Robinson RH, Meissler JJ, Fan X, et al. A CB2selective cannabinoid suppresses $\mathrm{T}$-cell activities and increases Tregs and IL-10. J Neuroimmune Pharmacol 2015;10:318-32.

47. Kong W, Li H, Tuma R, et al. Selective CB2 receptor agonist Gpla attenuates EAE through modulating CD4 $T$ cell differentiation and immune cell infiltration in the CNS (BA8P. 131). J Immnol 2014;192:113-4.

48. Ferrini M, Hong S, Roberts K, et al. Cannabinoid CB2 receptors as novel target for inhibiting house dust mite induced allergic airway inflammation (P6023). J Immnol 2013;190:120-2.

49. Elsakkar MG, Sharaki OA, Abdallah DM, et al. Adalimumab ameliorates OVA-induced airway inflammation in mice: Role of CD4+ CD25+ FOXP3+ regulatory T-cells. Eur J Pharmacol 2016;786:100-8.

(English Language Editor: K. Brown) 


\section{Appendix 1: Using immunomagnetic bead positive sorting technology to extract and sort mouse spleen-derived CD4 ${ }^{+}$T cells}

1) The BALB/c mice was quickly put to death use the cervical dislocation method, and then put most of them in the preprepared $75 \%$ alcohol to soak and disinfect for 5 minutes;

2) Take out the spleen aseptically and place it in a pre-prepared $15 \mathrm{ml}$ centrifuge tube containing an appropriate amount of RPMI-1640 medium on ice;

3) Shake gently to wash away the remaining blood and tissue residues on the surface of the fresh spleen for grinding;

4) Under dark conditions, put $4.5 \mathrm{ml}$ of lymphocyte separation solution in a $60 \mathrm{~mm}$ petri dish, cover the culture dish with a sterile 200 mesh nylon mesh and fully contact the lymphocyte separation solution;

5) Put the spleen in the center of the nylon membrane, Grind the piston vertically and evenly for about 3 minutes with moderate force, and shake it gently to disperse the cell clusters into the separation liquid;

6) After fully grinding, collect the cell suspension and transfer it to a sterile $15 \mathrm{ml}$ centrifuge tube, then draw $200 \mathrm{ul}$ of 1640 medium slowly into the centrifuge tube along the wall of the tube, keep the liquid level clear, and centrifuge for $30 \mathrm{~min}$ at $20^{\circ} \mathrm{C}$ and $800 \times \mathrm{g}$;

7) After the centrifugation, aspirate the middle cell layer into a dry and sterile $15 \mathrm{ml}$ centrifuge tube, then add $10 \mathrm{ml} 1640$ medium and mix upside down, wash twice, and centrifuge again at $20^{\circ} \mathrm{C}$ and $250 \times \mathrm{g}$ for 10 minutes.

8) Discard the supernatant, add 3-5 $\mathrm{ml} 1640$ medium to resuspend, after fully dissipating the cell mass, take 20ul cell suspension and add it to the blood cell counting plate to determine the number of mouse splenic mononuclear cells;

9) Counting formula: the total number of mononuclear cells $=[$ (the total number of cells in the 4 large cells on the counting plate) $/ 4] \times$ the dilution factor $\times 10^{4} / \mathrm{ml}$ ), and the cell viability is determined at the same time: the cells are suspended by the trypan blue exclusion method.

10) Mix the solution with $0.4 \%$ trypan blue staining solution $1: 1$ and count under a microscope. A total of 200 cells are counted within 5 minutes. Survival rate=number of live cells/total number of cells $\times 100 \%$.

11) The obtained spleen mononuclear cell suspension (counting completed) was washed once with ice PBS, centrifuged at $4^{\circ} \mathrm{C}$ and 300xg for 10 minutes, and the supernatant was discarded for sorting; Next, the magnetic bead sorter and the operating table were prepared.

12) The cells were resuspended at the ratio of $90 \mathrm{ul}$ magnetic bead sorting buffer per $10^{7}$ cells; immunomagnetic bead positive sorting technology was used to positively sort mouse CD4+ T cell subsets.

Table S1 Primers for CNR2, STAT5, ROR $\gamma \mathrm{t}$ and FOXP3

\begin{tabular}{lcc}
\hline Gene & Primer sequences (forward) & Primer sequences (reverse) \\
\hline CNR2 & ATGGCCGTGCTCTATATTATCCT & ATGGTCACACTGCCGATCTTC \\
STAT5 & CAGCCGTGGGATGCTATTGA & GGGACAGCGGTCATACGTG \\
FOXP3 & GACCCACACCTCACAAATTGA & AGTAGGCCACATTACACTGCT \\
GAPDH & CACCTATGCCACCCTTATCCG & CATGCGAGTAAACCAATGGTAGA \\
\hline
\end{tabular}

